\author{
Marquette University \\ e-Publications@Marquette
}

\title{
Conditional Spectrum Computation Incorporating Multiple Causal Earthquakes and Ground-Motion Prediction Models
}

Ting Lin

Marquette University, ting.lin@marquette.edu

Stephen C. Harmsen

Jack W. Baker

Stanford University

Nicolas Luco

Follow this and additional works at: https://epublications.marquette.edu/civengin_fac

Part of the Civil and Environmental Engineering Commons

\section{Recommended Citation}

Lin, Ting; Harmsen, Stephen C.; Baker, Jack W.; and Luco, Nicolas, "Conditional Spectrum Computation Incorporating Multiple Causal Earthquakes and Ground-Motion Prediction Models" (2013). Civil and Environmental Engineering Faculty Research and Publications. 116.

https://epublications.marquette.edu/civengin_fac/116 


\section{Bulletin of the Seismological Society of America}

This copy is for distribution only by

the authors of the article and their institutions in accordance with the Open Access Policy of the Seismological Society of America.

For more information see the publications section of the SSA website at www.seismosoc.org

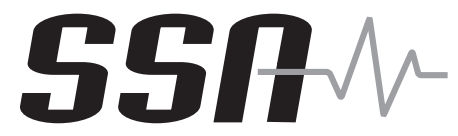

The Seismological Society of America 400 Evelyn Ave., Suite 201

Albany, CA 94706-1375

(510) 525-5474; FAX (510) 525-7204

www.seismosoc.org 


\title{
Conditional Spectrum Computation Incorporating Multiple Causal Earthquakes and Ground Motion Prediction Models
}

\author{
Ting Lin, Stephen C. Harmsen, Jack W. Baker, and Nicolas Luco
}

To appear in Bull. Seismol. Soc. Am. 103(2a).

\begin{abstract}
The Conditional Spectrum (CS) is a target spectrum (with conditional mean and conditional standard deviation) that links seismic hazard information with ground motion selection for nonlinear dynamic analysis. Probabilistic seismic hazard analysis (PSHA) estimates the ground motion hazard by incorporating the aleatory uncertainties in all earthquake scenarios and resulting ground motions as well as the epistemic uncertainties in ground motion prediction models (GMPMs) and seismic source models. Typical CS calculations to date are produced for a single earthquake scenario using a single GMPM, but more precise use requires consideration of at least multiple causal earthquakes and multiple GMPMs that are often considered in a PSHA computation. This paper presents the mathematics underlying these more precise CS calculations. Despite requiring more effort to compute than approximate calculations using a single causal earthquake and GMPM, the proposed approach produces an exact output that has a theoretical basis. To demonstrate the results of this approach and compare the exact and approximate calculations, several example calculations are performed for real sites in the western U.S. (WUS). The results also provide some insights regarding the circumstances under which approximate results are likely to closely match more exact results. To facilitate these more precise calculations for real applications, the exact CS calculations can now be performed for real sites in the U.S. using new deaggregation features in the U.S. Geological Survey hazard mapping tools. Details regarding this implementation are discussed in this paper.
\end{abstract}

\section{Introduction}

Ground motion selection for structural and geotechnical system analysis is often associated with a target response spectrum that is derived from probabilistic seismic hazard analysis (PSHA) results. The Conditional Spectrum (CS) is one such target spectrum that estimates the distribution (with mean and standard deviation) of the response spectrum, conditioned on the occurrence of a target spectral acceleration value at the period of interest. As this CS concept is considered for practical use, several common approximations need to be further explored. Typical CS calculations to date are produced for a single earthquake ground motion scenario (i.e., magnitude, distance, and ground motion intensity of interest), and computed using a single ground motion prediction 
model (GMPM, previously known as an attenuation relation, and also known as an ground motion prediction equation, a ground motion model, or a ground motion relation). The scenario is generally determined from PSHA deaggregation, but PSHA deaggregation calculations for real sites often show that multiple earthquake scenarios contribute to occurrence of a given ground motion intensity. Additionally, modern PSHA calculations are performed with multiple GMPMs using a logic tree that also includes seismic source models. Incorporating those features is thus necessary to compute a CS that is fully consistent with the PSHA calculations upon which it is based.

This paper presents the methodology for performing refined CS computations that precisely incorporate the aleatory uncertainties (which are inherently random) in earthquake events with all possible magnitudes and distances, as well as the epistemic uncertainties (which are due to limited knowledge) from multiple GMPMs and seismic source models. Three approximate calculation approaches and the exact calculation approach are presented, with increasing levels of complexity and accuracy. To demonstrate, several example calculations are performed for representative sites with different surrounding seismic sources: Stanford in northern California, Bissell in southern California, and Seattle in the Pacific Northwest. The results evaluate the exact and approximate calculations, and analyze factors that contribute to the differences in accuracy. Note that while the exact approach is more cumbersome, it does not need to be computed by the user, since these exact CS calculations have been implemented in the U.S. Geological Survey (USGS) seismic hazard mapping tools, and could be incorporated into other PSHA software as well. Details regarding this new tool, and issues related to implementation of these concepts, are provided below.

\section{Basic Conditional Spectrum computation}

A wide variety of techniques have been developed in the past to select ground motion inputs for nonlinear dynamic analysis (e.g., Haselton et al., 2009; Katsanos et al., 2010). One common approach involves selecting ground motions whose response spectra match the target spectrum (e.g., Watson-Lamprey and Abrahamson, 2006; Beyer and Bommer, 2007; ASCE, 2010; ATC, 2011). The Conditional Mean Spectrum (CMS) is one such spectrum that incorporates correlation across periods to estimate the expected $S a$ values at all periods $T_{i}\left(S a\left(T_{i}\right)\right)$ given the target $S a$ value at the period of interest $T^{*}\left(S a\left(T^{*}\right)\right.$ ) (e.g., Baker and Cornell, 2006; Somerville and Hamburger, 2009; Abrahamson and Al Atik, 2010; Gulerce and Abrahamson, 2011; Somerville and Thio, 2011; Baker, 2011).

The basic CMS computation procedure is as follows. First, obtain the target spectral acceleration at period $T^{*}, S a\left(T^{*}\right)$, from PSHA, and its associated mean causal earthquake magnitude $(M)$, distance $(R)$, and other parameters $(\theta)$, from deaggregation. Next, use a GMPM to obtain the logarithmic mean and standard deviation of $S a$ at all periods $T_{i}$, denoted as $\mu_{\ln S a}\left(M, R, \theta, T_{i}\right)$ and $\sigma_{\operatorname{lnSa}}\left(M, \theta, T_{i}\right)$. For any $S a\left(T_{i}\right)$ value, compute the $\varepsilon\left(T_{i}\right)$, the number of standard deviations by which $\ln S a\left(T_{i}\right)$ differs from the mean spectral ordinate predicted by a given GMPM, $\mu_{l n S a}\left(M, R, \theta, T_{i}\right)$, at $T_{i}$

$$
\varepsilon\left(T_{i}\right)=\frac{\ln S a\left(T_{i}\right)-\mu_{\ln S a}\left(M, R, \theta, T_{i}\right)}{\sigma_{\ln S a}\left(M, \theta, T_{i}\right)}
$$

The target $\varepsilon\left(T^{*}\right)$ (for the target $S a\left(T^{*}\right)$ value) can also be computed using Equation 1. We can then compute the conditional mean spectral acceleration at other periods $T_{i}, \mu_{\ln S a\left(T_{i}\right) \mid \ln S a\left(T^{*}\right)}$, using the correlation coefficient between pairs of $\varepsilon$ values at two periods, $\rho\left(\varepsilon\left(T_{i}\right), \varepsilon\left(T^{*}\right)\right.$ ) (hereinafter 
referred to as $\rho\left(T_{i}, T^{*}\right)$ ) (from e.g., Baker and Jayaram, 2008)

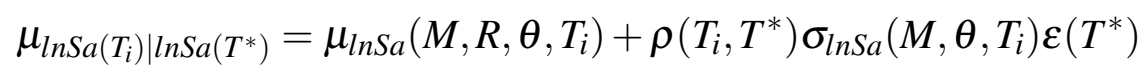

The spectrum defined by $\mu_{\operatorname{lnSa}\left(T_{i}\right) \ln S a\left(T^{*}\right)}$ in Equation 2 has been termed the "CMS", as it specifies the mean values of $\ln S a\left(T_{i}\right)$, the exponentials of which are equivalent to the median values of $S a\left(T_{i}\right)$ if it is lognormally distributed, conditional on the value of $\ln S a\left(T^{*}\right)$ (e.g., Baker, 2011).

Similarly, we can compute $\sigma_{\operatorname{lnSa}\left(T_{i}\right) \mid \ln S a\left(T^{*}\right)}$, the conditional standard deviation of spectral acceleration at period $T_{i}$, conditioned on the value of $S a$ at $T^{*}$

$$
\sigma_{\operatorname{lnSa}\left(T_{i}\right) \mid \ln S a\left(T^{*}\right)}=\sigma_{\ln S a}\left(M, \theta, T_{i}\right) \sqrt{1-\rho^{2}\left(T_{i}, T^{*}\right)}
$$

The conditional standard deviation $\sigma_{\ln S a\left(T_{i}\right)} \operatorname{lnSa}\left(T^{*}\right)$ from Equation 3, when combined with the conditional mean value $\mu_{\ln S a\left(T_{i}\right) \mid \operatorname{lnSa}\left(T^{*}\right)}$ from Equation 2, specifies a complete distribution of logarithmic spectral acceleration values at all periods (where the distribution at a given period is Gaussian, as justified by Jayaram and Baker (2008)). We term the resulting spectrum distribution as a "CS", to be distinguished from the "CMS" that does not consider the variability specified by Equation 3. It is noteworthy that as an extension of the CMS approach, Bradley (2010) proposed a generalized conditional intensity measure (GCIM) approach that considers the complete distribution of conditional intensity measures other than $\mathrm{Sa}$.

The input earthquake parameters required for the CS calculations above are those required by the GMPM, and can include magnitude $(M)$, distance $(R)$, and other parameters such as rupture mechanism and site conditions $(\theta)$. In this paper, we will sometimes use $M / R$ in the text as an abbreviation for $M / R / \theta$ (although $\theta$ will be included in equations where appropriate). To implement the CS in practice, we need to determine which $M / R$ and GMPM to use. Common approximations to compute the CS include using the mean magnitude and distance from deaggregation, along with a single GMPM (Baker, 2011). As explained more in the next section, these approximations need to be evaluated for the practical implementation of CS as a target spectrum for selecting ground motions.

\section{Deaggregation}

Computing CS at real sites requires us to consider the following two factors: First, deaggregation will produce multiple causal earthquake magnitude and distance values for a given $S a\left(T^{*}\right)$ amplitude, as illustrated in the USGS deaggregation plots in Figure 1, where the height of each column represents the percentage contribution from each $M / R$ combination. Second, PSHA calculations use multiple GMPMs and seismic source models to compute seismic hazard at a site through a logic tree (e.g., Kramer, 1996; McGuire, 2004; Scherbaum et al., 2005; Bommer and Scherbaum, 2008; Petersen et al., 2008). A refined CS computation, therefore, needs to consider multiple causal earthquakes and GMPMs, if not multiple seismic source models.

PSHA accounts for the aleatory uncertainties in earthquake events, by combining the frequencies of occurrence of all earthquake scenarios with different magnitudes and distances with predictions of resulting ground motion intensity, in order to compute seismic hazard at a site (e.g., Kramer, 1996; McGuire, 2004). PSHA also incorporates the epistemic uncertainties in the seismic source models and ground motion predictions, by considering multiple models in a logic tree. 
For instance, the USGS utilizes three GMPMs (Boore and Atkinson, 2008; Campbell and Bozorgnia, 2008; Chiou and Youngs, 2008) for crustal seismic sources in the WUS (Petersen et al., 2008). Traditional PSHA deaggregation (McGuire, 1995; Bazzurro and Cornell, 1999; Harmsen, 2001), however, only reports distributions of causal $M / R / \varepsilon$ values given an $S a$ amplitude. The McGuire (1995) deaggregation is conditional on $S a$ that equals a target value, termed " $S a$ occurrence", while the Bazzurro and Cornell (1999) deaggregation is conditional on Sa that exceeds a target value, termed "Sa exceedance". Depending on the $S a$ values of interest, either deaggregation approach can be used. Such deaggregation can be extended to include distributions of the logic tree branches, such as GMPMs, that contribute to predictions of $S a$ occurrence (or exceedance).

Just as the deaggregation of magnitude and distance identifies the relative contribution of each earthquake scenario to $S a$ occurrence (or exceedance), the deaggregation of GMPMs tells us the probability that the occurrence (or exceedance) of that $S a$ level is predicted by a specific GMPM. Note that the GMPM deaggregation weights differ from the logic-tree weights; in decision analysis (e.g., Benjamin and Cornell, 1970), the logic-tree weights are equivalent to prior weights, whereas the deaggregation weights may be interpreted as posterior weights given the occurrence (or exceedance) of the ground motion amplitude of interest. Additional details on GMPM deaggregation are provided in Lin and Baker (2011). For the purpose of response spectrum predictions, the key elements are the GMPMs and their input earthquake parameters (e.g., $M, R, \varepsilon$ ). Hence, the focus of deaggregation here will be on these two. The other portions of the logic tree (e.g., recurrence type, rates, maximum magnitude) do not influence spectrum predictions and so can be grouped for the purpose of these calculations. The USGS has recently begun providing GMPM deaggregation outputs (see Data and Resources section near the end of this paper). These outputs facilitate the exact calculations of CS described below.

\section{Conditional Spectrum Calculation Approaches}

We now consider several options for computing CS that incorporate consideration of multiple causal earthquake scenarios and multiple GMPMs, as well as multiple seismic source models and their logic-tree branches. We introduce several approximate calculation approaches with increasing complexity but also with increasing accuracy, followed by the exact calculation. Differences between the approaches are highlighted, and these approaches are evaluated later to determine the accuracy of the approximate approaches.

\section{Method 1: Approximate CS using mean $M / R$ and a single GMPM}

The most basic method for computing an approximate CS is to utilize a single earthquake scenario and single GMPM, so that Equations 2 and 3 can be used directly. In current practice, this is done by taking the mean value of the causal magnitudes and distances from deaggregation, denoted here as $\bar{M}$ and $\bar{R}$ (Baker, 2011). Similarly, the mean value of other causal parameters $(\bar{\theta})$ can be obtained or inferred from deaggregation. These mean values can then be used with a single GMPM (even though the underlying hazard analysis utilized several GMPMs). The resulting CS calculations are given below, utilizing subscript $k$ 's to denote that the calculations are based on a single GMPM indexed by $k$. The equations are also denoted as being approximately equal to the true CS values, 
given the simplifications made here.

$$
\begin{gathered}
\mu_{\operatorname{lnSa}, k\left(T_{i}\right) \mid \operatorname{lnSa}\left(T^{*}\right)} \approx \mu_{\operatorname{lnSa}, k}\left(\bar{M}, \bar{R}, \bar{\theta}, T_{i}\right)+\rho\left(T_{i}, T^{*}\right) \sigma_{\operatorname{lnSa}, k}\left(\bar{M}, \bar{\theta}, T_{i}\right) \bar{\varepsilon}\left(T^{*}\right) \\
\sigma_{\operatorname{lnS} a, k\left(T_{i}\right) \mid \operatorname{lnSa}\left(T^{*}\right)} \approx \sigma_{\operatorname{lnSa}, k}\left(\bar{M}, \bar{\theta}, T_{i}\right) \sqrt{1-\rho^{2}\left(T_{i}, T^{*}\right)}
\end{gathered}
$$

where the mean and standard deviation predicted by GMPM $k$ are denoted $\mu_{\operatorname{lnSa,k}(}$ and $\sigma_{\operatorname{lnSa}, k}$, and

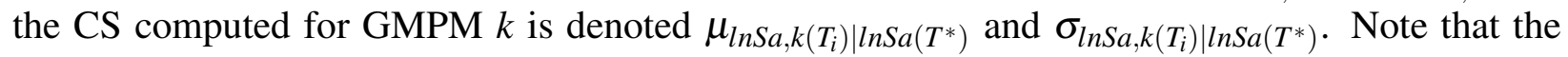
correlation coefficient, $\rho$, is assumed to be constant for each GMPM - this could be revised if desired.

\section{Method 2: Approximate CS using mean $M / R$ and GMPMs with logic-tree weights}

We can refine Method 1 above by considering all GMPMs used in the PSHA computation. The PSHA logic tree weights each model (these weights can be equal or unequal), and here we denote the weight for model $k$ as $p_{k}^{l}$ where the superscript $l$ refers to logic-tree. To obtain an approximate CS using all of these GMPMs, we repeat the single-GMPM calculation (Equations 4 and 5) to obtain $\mu_{\ln S a, k\left(T_{i}\right) \mid \ln S a\left(T^{*}\right)}$ and $\sigma_{\ln S a, k\left(T_{i}\right) \mid \ln S a\left(T^{*}\right)}$ for each GMPM. We then sum up the resulting mean spectra $\left(\mu_{\ln S a\left(T_{i}\right) \mid \ln S a\left(T^{*}\right)}\right)$, weighted by the logic-tree weights, to get a mean spectrum

$$
\mu_{\operatorname{lnSa}\left(T_{i}\right) \mid \operatorname{lnSa}\left(T^{*}\right)} \approx \sum_{k} p_{k}^{l} \mu_{\operatorname{lnSa}, k\left(T_{i}\right) \mid \ln S a\left(T^{*}\right)}
$$

The computation of conditional standard deviations is slightly more complicated, as it not only accounts for the mean of the standard deviations from the GMPMs, but also includes the additional uncertainty introduced by the variation in mean predictions among the GMPMs. Formal probabilistic modeling (e.g., Ditlevsen, 1981) can be used to show that the resulting conditional standard deviation is

$$
\sigma_{\operatorname{lnSa}\left(T_{i}\right) \mid \operatorname{lnSa}\left(T^{*}\right)} \approx \sqrt{\sum_{k} p_{k}^{l}\left(\sigma_{\ln S a, k\left(T_{i}\right) \mid \ln S a\left(T^{*}\right)}^{2}+\left(\mu_{\operatorname{lnSa}, k\left(T_{i}\right) \mid \ln S a\left(T^{*}\right)}-\mu_{\ln S a\left(T_{i}\right) \mid \ln \operatorname{Sa}\left(T^{*}\right)}\right)^{2}\right)}
$$

In Equations 6 and 7, we no longer have a subscript $k$ on the resulting $\mu_{\ln \operatorname{Sa}\left(T_{i}\right) \mid \ln \operatorname{Sa}\left(T^{*}\right)}$ and $\sigma_{\ln S a\left(T_{i}\right) \mid \ln \operatorname{Sa}\left(T^{*}\right)}$, since the results are no longer specific to a single GMPM but incorporate multiple GMPMs.

While the use of logic-tree weights is not rigorously correct, we introduce it here as a convenient approximation because these equations do not require GMPM deaggregation outputs, which are not currently available from many PSHA software tools.

\section{Method 3: Approximate CS using GMPM-specific mean $M / R$ and GMPMs with deaggregation weights}

In this section, we further refine the CS calculations by taking advantage of GMPM deaggregation if it is available (e.g., as it is from the new USGS tools). First, GMPM deaggregation will provide separate $M / R$ deaggregation for each prediction model. Here we will use the mean $M$ and $R$ values 
for each model, denoted as $\bar{M}_{k}$ and $\bar{R}_{k}$ for GMPM $k$. Using these values, means and standard deviations of the CS can be computed for GMPM $k$ as follows

$$
\begin{gathered}
\mu_{\operatorname{lnSa}, k\left(T_{i}\right) \mid \operatorname{lnSa}\left(T^{*}\right)} \approx \mu_{\operatorname{lnSa}, k}\left(\bar{M}_{k}, \bar{R}_{k}, \bar{\theta}_{k}, T_{i}\right)+\rho\left(T_{i}, T^{*}\right) \sigma_{\operatorname{lnSa}, k}\left(\bar{M}_{k}, \bar{\theta}_{k}, T_{i}\right) \bar{\varepsilon}_{k}\left(T^{*}\right) \\
\sigma_{\operatorname{lnSa}, k\left(T_{i}\right) \mid \operatorname{lnSa}\left(T^{*}\right)} \approx \sigma_{\operatorname{lnSa}, k}\left(\bar{M}_{k}, \bar{\theta}_{k}, T_{i}\right) \sqrt{1-\rho^{2}\left(T_{i}, T^{*}\right)}
\end{gathered}
$$

Note that the GMPM-specific $\bar{M}_{k}$ and $\bar{R}_{k}$ (in Equations 8 and 9) are different from the $\bar{M}$ and $\bar{R}$ with respect to all GMPMs (in Equations 4 and 5). As an intermediate step (between e.g., $\bar{R}$ and $\bar{R}_{k}$ ), the concept of conditional deaggregation given GMPM can also be extended to compute $\bar{M}_{k}$, $\bar{R}_{k} \mid \bar{M}_{k}$, and $\bar{\varepsilon}_{k} \mid \bar{M}_{k}, \bar{R}_{k}$ in a cascading or Rosenblatt-distribution manner.

The second GMPM deaggregation output used in this method is the probability that GMPM $k$ predicted occurrence (or exceedance) of the $S a$. These deaggregation probabilities are denoted as $p_{k}^{d}$ where the superscript $d$ refers to deaggregation, and they are generally not equal to the PSHA logic-tree weights that have been denoted as $p_{k}^{l}$. Utilizing these weights, along with the GMPMspecific $\mu_{\ln S a, k\left(T_{i}\right) \mid \ln S a\left(T^{*}\right)}$ and $\sigma_{\ln S a, k\left(T_{i}\right) \mid \ln S a\left(T^{*}\right)}$ from Equations 8 and 9, a composite CS can be computed

$$
\begin{gathered}
\mu_{\ln S a\left(T_{i}\right) \mid \operatorname{lnSa}\left(T^{*}\right)} \approx \sum_{k} p_{k}^{d} \mu_{\operatorname{lnSa}, k\left(T_{i}\right) \mid \ln S a\left(T^{*}\right)} \\
\sigma_{\ln S a\left(T_{i}\right) \mid \operatorname{lnSa}\left(T^{*}\right)} \approx \sqrt{\sum_{k} p_{k}^{d}\left(\sigma_{\ln S a, k\left(T_{i}\right) \mid \operatorname{lnSa}\left(T^{*}\right)}^{2}+\left(\mu_{\operatorname{lnSa}, k\left(T_{i}\right) \mid \operatorname{lnSa}\left(T^{*}\right)}-\mu_{\left.\left.\ln \operatorname{Sa}\left(T_{i}\right) \mid \ln \operatorname{Sa}\left(T^{*}\right)\right)^{2}\right)}\right.\right.}
\end{gathered}
$$

As with Method 2, the mean spectrum is the mean (over GMPMs) of the GMPM-specific means, except that here we have utilized the more appropriate deaggregation weights $p_{k}^{d}$. The standard deviation of the spectrum again contains contributions from the individual GMPM conditional standard deviations, plus the uncertainty from the variations in mean spectra across GMPMs. While this method incorporates more exact information than Methods 1 or 2, it is still approximate in that it utilizes only the mean earthquake scenario for a given GMPM. Method 4 will resolve that final approximation.

\section{Method 4: "Exact" CS using multiple causal earthquake $M / R$ and GMPMs with deaggregation weights}

With this final method we now account exactly for, when we compute the CS, the contribution that each earthquake magnitude/distance and each GMPM makes to the seismic hazard. For each causal earthquake combination $M_{j} / R_{j}$ and GMPM $k$, we can obtain a corresponding mean and standard deviation of the CS (denoted $\mu_{\ln S a, j, k\left(T_{i}\right) \mid \ln S a\left(T^{*}\right)}$ and $\sigma_{\ln S a, j, k\left(T_{i}\right) \mid \ln S a\left(T^{*}\right)}$ ) as follows

$$
\begin{gathered}
\mu_{\operatorname{lnSa}, j, k\left(T_{i}\right) \mid \operatorname{lnSa}\left(T^{*}\right)}=\mu_{\operatorname{lnSa,k}}\left(M_{j}, R_{j}, \theta_{j}, T_{i}\right)+\rho\left(T^{*}, T_{i}\right) \varepsilon_{j}\left(T^{*}\right) \sigma_{\operatorname{lnSa}, k}\left(M_{j}, \theta_{j}, T_{i}\right) \\
\sigma_{\operatorname{lnS} a, j, k\left(T_{i}\right) \mid \operatorname{lnS} a\left(T^{*}\right)}=\sigma_{\operatorname{lnSa}, k}\left(M_{j}, \theta_{j}, T_{i}\right) \sqrt{1-\rho^{2}\left(T_{i}, T^{*}\right)}
\end{gathered}
$$

A PSHA deaggregation that includes GMPM deaggregation will provide the weights, $p_{j, k}^{d}$, that indicate the contribution of each $M_{j} / R_{j}$ and $G M P M_{k}$ to occurrence (or exceedance) of the $\mathrm{Sa}$ of interest. Note that here we are considering the contributions of individual $M_{j} / R_{j}$ rather 
than approximating all contributing earthquake scenarios by simply a mean $M$ and $R$, as we did in Equations 8 and 9. The exact CS incorporating multiple $M / R$ and GMPMs can then be evaluated by combining these individual $\mu_{\operatorname{lnSa,j,k}\left(T_{i}\right) \mid \ln S a\left(T^{*}\right)}$ and $\sigma_{\operatorname{lnSa}, j, k\left(T_{i}\right) \mid \ln S a\left(T^{*}\right)}$ with their corresponding weights, $p_{j, k}^{d}$

$$
\begin{gathered}
\mu_{\operatorname{lnSa}\left(T_{i}\right) \mid \operatorname{lnSa}\left(T^{*}\right)}=\sum_{k} \sum_{j} p_{j, k}^{d} \mu_{\operatorname{lnSa}, j, k\left(T_{i}\right) \mid \ln S a\left(T^{*}\right)} \\
\sigma_{\ln S a\left(T_{i}\right) \mid \ln S a\left(T^{*}\right)}=\sqrt{\sum_{k} \sum_{j} p_{j, k}^{d}\left(\sigma_{\ln S a, j, k\left(T_{i}\right) \mid \ln S a\left(T^{*}\right)}^{2}+\left(\mu_{\ln S a, j, k\left(T_{i}\right) \mid \ln S a\left(T^{*}\right)}-\mu_{\left.\left.\ln S a\left(T_{i}\right) \mid \ln S a\left(T^{*}\right)\right)^{2}\right)}\right.\right.}
\end{gathered}
$$

The above equations are similar to those in Method 3, except that there is now a second set of summations in the equations to account for the effect of multiple $M_{j} / R_{j}$ values instead of the single mean values $\bar{M}_{k}$ and $\bar{R}_{k}$ from Method 3 . These equations provide an exact answer to the question, what is the mean and standard deviation of the response spectra associated with ground motions having a target $S a\left(T^{*}\right)$, when that $S a\left(T^{*}\right)$ could potentially result from multiple earthquake scenarios, and the $S a$ predictions come from a logic tree with multiple GMPMs? It requires more effort to compute than the approximate approaches commonly used today, and requires detailed deaggregation information including hazard contributions of GMPMs and other parameters, $\theta$, that may not be available.

Alternatively, an exact CS can be computed directly from the earthquake parameters and GMPMs that were used in PSHA computation to aggregate the hazard, as described in the next section. Although treatments of aleatory and epistemic uncertainties are often separated in PSHA, a single seismic hazard curve is typically derived with the consideration of aleatory uncertainties from multiple causal earthquakes and epistemic uncertainties from multiple GMPMs and seismic source models (e.g., Petersen et al., 2008). Here we take a similar approach to compute a single CS that combines these aleatory and epistemic uncertainties.

\section{Aggregation approach to Method 4 (exact CS)}

While the GMPM deaggregations used in Methods 3 and 4 are now available from the USGS, it would be impractical to provide deaggregations with respect to all of the other branches of the PSHA logic tree (e.g., for alternative moment-area equations in California and for body wave to moment magnitude equations in the central and eastern U.S. (CEUS)). Likewise it would be cumbersome to provide deaggregations with respect to all of the other GMPM input parameters besides $M$ and $R$ (e.g., rupture mechanism and hanging/foot-wall indicators), which are denoted above as $\theta$. To account for these other branches and parameters in Method 4 without additional deaggregation results, during the PSHA computation a CS can be calculated (using Equations 12 and 13) for each and every earthquake source and logic-tree branch. These numerous CS results can then be combined using Equations 14 and 15, but now with $j$ representing all the earthquake sources and $k$ representing all the logic-tree branches. In this case, the deaggregation weights in the equations are simply taken from the PSHA contribution (mean annual exceedance frequency) for each earthquake source and logic-tree branch, normalized by the total aggregated hazard.

An advantage of this aggregation approach to Method 4 is that the other GMPM input parameters $\theta$ no longer need to be inferred in calculating a CS. This is because, as explained above, we 
can first calculate a CS for each and every earthquake source (not to mention logic tree branch) using the same corresponding GMPM input parameters used in the PSHA computation. Based on the examples for three sites presented below, any numerical differences between the aggregation approach and Method 4 are not expected to be significant for the CMS (or mean CS) at a site. Also based on the examples, however, the standard deviation of a CS (via Equation 15) using the results for every earthquake source and logic-tree branch would be expected to yield differences although the practical significance of the differences is not known. The standard deviation from the aggregation approach would capture all of the uncertainties considered in the PSHA computation.

An implementation of this aggregation approach to calculating an exact CS is now provided as part of USGS online hazard tools. Details and limitations of this implementation are discussed in the final section on "Conditional Spectrum calculation tools from USGS".

\section{Example Calculations for Three Sites}

To demonstrate the numerical results that are now available using the above equations and USGS online hazard tools, this section provides a set of example calculations to determine whether using the "exact" Method 4 provides results that have practical differences from those obtained using the simpler approximate Methods 1 to 3.

To evaluate the accuracy of the approximate methods, CS for three locations are computed using the methods described above. Target spectral accelerations are obtained for $S a(0.2 s)$ with $10 \%$ probability of exceedance in 50 years (i.e., a return period of 475 years), and for $S a(1 s)$ with $2 \%$ probability of exceedance in 50 years (i.e., a return period of 2475 years).

\section{Description of example sites and GMPMs}

We consider three locations in the WUS with relatively high hazard but differing surrounding seismic sources: Stanford, Bissell, and Seattle. Deaggregation results for these three sites are shown in Figure 1. Ground motion hazard at Stanford, located in northern California, is dominated by a single shallow crustal earthquake source, the San Andreas fault zone. Ground motion hazard at Bissell, located in southern California, has contributions from multiple earthquake sources but they are all shallow crustal sources. Ground motion hazard at Seattle has contributions from multiple earthquake sources of different types - shallow crustal, and subduction zone interface and intraplate (each of which has its own set of GMPMs). All three sites are assumed to have a timeaveraged shear-wave velocity in the top 30 meters of the soil $\left(V_{S 30}\right)$ of $760 \mathrm{~m} / \mathrm{s}$.

The hazard calculations and deaggregation results all come from the USGS models and hazard mapping tools. The USGS model (Petersen et al., 2008) assigns equal logic-tree weights to GMPMs near Stanford and Bissell, but unequal logic-tree weights to GMPMs near Seattle. The USGS model uses three GMPMs for the crustal sources near Stanford, Bissell, and Seattle (Boore and Atkinson, 2008; Campbell and Bozorgnia, 2008; Chiou and Youngs, 2008), three GMPMs for the subduction zone interface sources (Youngs et al., 1997; Atkinson and Boore, 2003; Zhao et al., 2006), and three GMPMs for the intraplate sources near Seattle (Youngs et al., 1997; Atkinson and Boore, 2003, which provides models that can be used in both Global and Cascadia regions). The Youngs et al. (1997), Atkinson and Boore (2003), and Zhao et al. (2006) models are developed for both subduction zone interface and intraplate sources. The GMPMs vary in their required input 
variables. The mean $\ln S a$ predictions depend on $M, R$, and other source and site characteristics $(\theta)$ such as depth to top of rupture, faulting mechanism, and hanging wall effect. Some of the GMPMs predict standard deviations of $\ln S a$ that depend only on the period of interest (e.g., Boore and Atkinson, 2008), while others are magnitude-dependent (e.g., Chiou and Youngs, 2008).

\section{Deaggregation information}

The target $S a(0.2 s)$ with $10 \%$ probability of exceedance in 50 years and $S a(1 s)$ with $2 \%$ probability of exceedance in 50 years are obtained from PSHA for the three example sites considered. The associated causal earthquake magnitudes and distances are obtained from USGS deaggregation (see Data and Resources Section) and their deaggregation plots are shown in Figure 1. Other parameters, $\theta$, that are associated with each causal earthquake $M / R$ combination can be obtained directly from the parameters that were used for PSHA computation (i.e., via the aggregation approach to Method 4), from deaggregation outputs if available, or inferred from the characteristics of contributing earthquake sources. With the target $S a\left(T^{*}\right)$ and $\mu_{\operatorname{lnSa}}\left(M, R, \theta, T^{*}\right)$ and $\sigma_{\operatorname{lnSa}}\left(M, \theta, T^{*}\right)$ predictions for each causal $M / R / \theta$, we can then back-calculate $\varepsilon\left(T^{*}\right)$ using Equation 1 . The logic-tree weights for each GMPM $\left(p_{k}^{l}\right)$ are obtained from the USGS documentation (Petersen et al., 2008), and the deaggregation weights ( $p_{k}^{d}$ and $p_{j, k}^{d}$ ) are obtained from the USGS deaggregation tools (see Data and Resources Section).

\section{Conditional Spectra results}

CS can be computed for each example case using the approximate or exact methods described above. Depending on the level of approximation, the CS for a GMPM $k$ can be computed using Method 1 (Equations 4 and 5) for approximate CS with mean $M / R(\bar{M}$ and $\bar{R}$ ), Method 3 (Equations 8 and 9) for approximate CS with GMPM-specific mean $M / R\left(\bar{M}_{k}\right.$ and $\left.\bar{R}_{k}\right)$, or Method 4 (Equations 12 and 13) for all contributing CS with GMPM-specific causal earthquake $M / R\left(M_{j}\right.$ and $\left.R_{j}\right)$. The composite CS can then be computed with the corresponding weights, using Method 2 (Equations 6 and 7) for approximate CS with GMPM logic-tree weights $\left(p_{k}^{l}\right)$, Method 3 (Equations 10 and 11) for approximate CS with GMPM deaggregation weights $\left(p_{k}^{d}\right)$, or Method 4 (Equations 14 and $15)$ for exact CS with deaggregation weights associated with each causal earthquake and GMPM $\left(p_{j, k}^{d}\right)$. The resulting CS obtained from these four Methods are plotted in Figure 2. Also plotted in the figure are the CMS (but not conditional standard deviations) resulting from the aggregation approach to Method 4, which are nearly identical to the Method 4 results despite the inclusion of additional logic-tree branches and earthquake sources. These CMS are obtained from the USGS calculation tools described below in the final section.

We can make several observations from the results of Figure 2. For the Stanford and Bissell sites, CS computed using Method 1 are very similar to results from Methods 2 and 3, but they differ more for Seattle. This is because the GMPMs used in Seattle, some of which are for subduction zone events, result in more varied predictions; using a mean $\bar{M} / \bar{R}$ that represents a variety of earthquake sources with a GMPM appropriate for a single source type could be anticipated to produce these varied predictions. For Seattle, Methods 2 and 3, which more carefully address the contributions of multiple GMPMs, do a better job of approximating the exact results from Method 4. 
For all three sites, the approximate Methods 2 and 3 work better for conditional mean estimation than for conditional standard deviation estimation compared to the exact Method 4, as Method 4 produces higher conditional standard deviations in every case. A closer examination of Equation 15 reveals two components of contribution to the exact conditional standard deviations: first, a contribution from $\sigma_{l n S a}$, that is, variance in $\operatorname{lnSa}$ for a given $M_{j} / R_{j} \& G M P M_{k}$; second, a contribution from $\mu_{l n S a}$, due to variation in $M_{j} / R_{j} \& G M P M_{k}$. In other words, the total variance comes from the expectation of the variance, which is the first term, and the variance of the expectation, which is the second term (e.g., Ditlevsen, 1981). The individual contributions from these two terms are plotted in Figure 3a-c. Methods 2 and 3 very closely approximate the contribution from $\sigma_{l n S a}$ for the Stanford and Bissell sites, although the match is not as good for Seattle. Method 4 also includes the contribution from $\mu_{\operatorname{lnSa}}$, which is, however, not well captured by Methods 2 and 3. Figure 3d-f show the $\mu_{l n S a}$ predicted for each $M_{j} / R_{j} \& G M P M_{k}$, and it is the weighted variance of these spectra that creates the contribution to the overall standard deviation from $\mu_{\operatorname{lnSa} a}$. We thus see that this "variance of expectations" contribution may not be negligible, and the approximate methods do not capture this well because they consider only mean $M / R$ values and thus cannot identify the contribution to uncertainty from multiple $M / R$ contributions to ground motion hazard. Similarly, we anticipate that the deaggregation approach to the exact Method 4 underestimates the conditional standard deviation, relative to the aggregation approach that accounts for every logic tree branch and earthquake source used in the PSHA computation. We do not yet know whether this underestimation is practically significant.

Figure 4 shows the target CS computed using Methods 2 and 4 for all three sites and both target $S a$ values: $S a(0.2 s)$ with $10 \%$ probability of exceedance in 50 years and $S a(1 s)$ with $2 \%$ probability of exceedance in 50 years. Method 2 is chosen as the reference approximate method here because it has an appealing combination of incorporating multiple GMPMs but not requiring any GMPM deaggregation information. For all three sites, the approximate and exact methods' mean estimates are in close agreement, while the approximate standard deviations underestimate the exact result - this effect is most pronounced at periods far from the conditioning period (i.e., $0.2 \mathrm{~s}$ or $1 \mathrm{~s})$.

The Method 2 approximation appears to work best for sites with a single earthquake source (e.g., Stanford), followed by sites with multiple earthquakes sources of the same type (e.g., Bissell) and sites with multiple differing earthquake source types (e.g., Seattle). This is because there are several contributing factors to the accuracy of the approximation: (1) the input causal earthquake parameters; (2) the GMPMs used; (3) the GMPM deaggregation weights.

First, the importance of considering multiple causal $M / R$ values depends upon how many $M / R$ values contribute significantly to the hazard. In cases where all contributions to hazard come from a narrow range of magnitudes and distances (e.g., Stanford), the mean $M / R$ is representative of the most important individual contributing $M / R$, so computations based only on the mean $M / R$ are very precise. However, in cases where hazard contributions come from a broader range of magnitudes and distances (especially in the case of Seattle), the mean $M / R$ deviates from any individual contributing $M / R$, so computations based on the mean $M / R$ only may result in a slight shift in conditional mean estimates in addition to reduced conditional standard deviations. Similarly, for the common situation of low- or moderate-seismicity sites in the CEUS, e.g., those that are located several hundred kilometers from the New Madrid seismic region where the low-frequency deaggregation can be strongly bimodal, computations based on the mean $M / R$ only may not be precise. Furthermore, variation in other parameters besides $M$ and $R$, such as depth to the top of rupture for 
different source types, can also affect the accuracy of the approximation since they contribute to the $S a$ prediction.

Second, the similarity of the GMPMs affects approximations in their treatment. For cases where the ground motion predictions for a given $M / R$ vary significantly between models (e.g., Seattle, where the subduction zone and crustal prediction models vary significantly), approximate treatment of GMPMs is less effective and so a CS using a single GMPM (or using approximate weights on multiple models) may produce inaccurate results. Similar inaccuracies can be expected in the CEUS. On the other hand, the three GMPMs used at Stanford and Bissell all tend to produce similar predictions, so for those cases the choice of the GMPM used to compute CS may not be as critical.

Third, as the GMPM deaggregation weights differ more from the GMPM logic-tree weights, approximate treatment of those weights works less effectively. For instance, in the (not too uncommon) case where one GMPM strongly dominates the deaggregation, the approximation that assumes GMPM logic-tree weights is expected to deviate more substantially from the computation that utilizes GMPM deaggregation weights. The GMPM deaggregation weights vary with the period of interest $\left(T^{*}\right)$, the target $S a\left(T^{*}\right)$ amplitude of interest, and the location, so it is difficult to develop simple rules for when the approximations work well. But if the GMPM predictions are similar to each other for the $M / R$ values contributing significantly to hazard, then the deaggregation weights are often similar to the logic-tree weights and the predictions are also in good agreement (as noted in the previous paragraph), so the approximations are generally good in those cases.

\section{Impact of Approximations on Ground Motion Selection}

The importance of approximations in the CS computations will depend upon how the results affect any engineering decisions that may be made. The most common use for a CS is as a target response spectrum for ground motion selection and scaling (Baker and Cornell, 2006; Baker, 2011). Approximations to the CS might have an influence on ground motions selected from a database (because the selected ground motions match the target response spectrum), and that could affect nonlinear dynamic analysis results. On the other hand, the finite size of recorded ground motion databases means that minor changes in the spectrum target may not result in substantially different ground motions being selected, and in that case the approximations would not have an appreciable impact on structural analysis results.

To illustrate, the target CS mean and variance are computed using both the exact (Method 4) and approximate (Method 2) approaches, at the Bissell site for the $S a(0.2 s)$ amplitude with $10 \%$ probability of exceedance in 50 years. Ground motions can be selected to match these target spectrum mean and variance using the procedure of Jayaram et al. (2011), which assumes a Gaussian distribution. In general the conditional logarithmic $S a$ distribution is not Gaussian when multiple causal earthquakes and/or multiple GMPMs are considered, and hence the mean and variance alone may not describe the entire distribution; they still provide useful insights, however. Alternatively, Bradley (2010) considers multiple causal earthquake sources and the complete distribution of the conditional ground motion intensity measure. The target response spectra and corresponding ground motions selected via Jayaram et al. (2011) are shown in Figures 4b and 5. The means of the CS using both methods are in close agreement, but the standard deviation of the CS using Method 4 
is higher than that using Method 2, especially at periods further away from the conditioning period of 0.2s. Consequently, the spectra of the ground motions selected using Method 4 are expected to show a similar mean but a higher standard deviation than those using Method 2. The larger exact CS standard deviation results in selecting a few more ground motions with high spectra at periods other than $0.2 \mathrm{~s}$, and this can result in a slightly increased probability of observing large structural responses or collapses (as seen in, e.g., Jayaram et al., 2011). Note that the spectra of the selected ground motion sets, however, do not differ substantially in Figure 5, relative to variations between ground motion spectra within a set. Structural analyses to date suggest that in cases such as this, the exact method results in similar median but increased dispersion in structural response estimates.

The difference in structural response can be larger, however, if Methods 2 and 4 result in substantial differences in both the mean and the variance of the CS, such as those illustrated in Figure $4 \mathrm{c}$ and $\mathrm{f}$ for the Seattle site. In such cases, in addition to a slight increase in structural response dispersion, the median of the structural response may shift as well. To reflect contributions from different earthquake sources, individual CS can be constructed for each earthquake source, and separate sets of ground motions selected to match both the target spectra as well as other characteristics of each source (Goda and Atkinson, 2011). These CS for different earthquake sources are available as intermediate steps to compute the exact CS described above, and are provided by the USGS as part of the CMS feature that is described in the next section. As the difference between approximate and exact spectra increases, more refined target spectra will have increasing benefits for ground motion selection and structural response assessment.

\section{Conditional Spectrum Calculation Tools from USGS}

The USGS National Seismic Hazard Mapping Project website now provides an option for CMS, as part of the 2008 Interactive Deaggregations web tool (see Data and Resources section). The spectra are consistent with the 2008 National Seismic Hazard Maps for the continental United States, and are computed via the section "Aggregation approach to Method 4 (exact CS)" described above. Described below are the inputs to and outputs from the tool, issues with the current implementation, and future features. One such future feature is providing the standard deviations of CS in addition to the means.

\section{Description of calculation tool}

As shown in Figure 6, the USGS 2008 Interactive Deaggregation web tool provides CMS for a user-specified

- location (address or latitude and longitude) anywhere in the continental United States;

- mean exceedance probabilities of $1 \%, 2 \%, 5 \%, 10 \%, 20 \%$, or $50 \%$ in 30, 50, 75, 100 or 200 years;

- spectral acceleration period of $0 \mathrm{~s}$ (corresponding to peak ground acceleration), $0.1 \mathrm{~s}, 0.2 \mathrm{~s}$, $0.3 \mathrm{~s}, 0.5 \mathrm{~s}, 1 \mathrm{~s}$, or $2 \mathrm{~s}$, or additionally $3 \mathrm{~s}, 4 \mathrm{~s}$, or $5 \mathrm{~s}$ for locations in the WUS (west of -115 degrees longitude); 
- $V_{S 30}$ of soil between 180 to $1300 \mathrm{~m} / \mathrm{s}$ for locations in the WUS, of 760 or $2000 \mathrm{~m} / \mathrm{s}$ in the CEUS (east of -100 degrees longitude), or of $760 \mathrm{~m} / \mathrm{s}$ for locations in between.

As output, the tool currently provides graphs, tables, and text files for four different types of CMS, all calculated according to the section "Aggregation approach to Method 4 (exact CS)" described above. The four different types are:

- an overall CMS that accounts for all of the earthquake sources and logic tree branches considered in the USGS PSHA computation (with a few exceptions described in the next section below);

- a CMS for each GMPM that accounts for all of the earthquake sources and logic tree branches related to the particular GMPM;

- a CMS for each of several (currently seven) $M / R / \varepsilon$ bins that contribute most to the total aggregated hazard, accounting for all of the earthquake sources and logic tree branches within that bin;

- a CMS for each $M / R / \varepsilon$ bin and GMPM (currently only in text output), accounting for all of the earthquake sources and logic tree branches within the bin that are related to the particular GMPM.

The CMS for each GMPM demonstrates the effect of using only a single GMPM. As mentioned above, this effect can be particularly significant in cases when more than one earthquake source type (e.g., subduction zone, shallow crustal) contributes significantly to the total aggregated hazard. In such cases, the CMS for two or more $M / R / \varepsilon$ bins and/or GMPMs, each corresponding to a different source type, may be more useful than a single overall CMS.

\section{Current implementation issues}

While the web tool implementation described above accounts for practically all of the earthquake sources and logic-tree branches considered in computing the USGS 2008 National Seismic Hazard Maps, there are some exceptions. The least significant of these is that CMS calculations are not carried out for earthquake sources that do not contribute appreciably to the total aggregated hazard (i.e., those with mean annual exceedance frequency less than $10^{-6}$ ). Also for the sake of limiting computation time, CMS are not calculated for the two USGS logic-tree branches that quantify additional epistemic uncertainty amongst the GMPMs for shallow crustal earthquakes in the WUS (see Petersen et al. (2008) for details). The logic tree branches corresponding to the GMPMs themselves are fully accounted for, however. In the CEUS, the USGS logic tree branch for temporal clustering of New Madrid Seismic Zone earthquakes is not yet incorporated into the 2008 Interactive Deaggregations web tool, and hence is not accounted for in the CMS calculations. The numerical impacts of these exceptions on the calculated CMS have not yet been quantified, but they are anticipated to be relatively insignificant.

In being consistent with the 2008 National Seismic Hazard Maps, the USGS web tool utilizes several different GMPMs for shallow crustal, subduction zone, and stable continental earthquake sources. However, for the correlation coefficients needed to calculate CS, the tool currently only 
uses the Baker and Jayaram (2008) model, which was developed with ground motion data exclusively from shallow crustal earthquakes. A recent study of subduction zone ground motions from Japan suggests that this correlation model is also a reasonable representation for subduction zone earthquake sources (Jayaram et al., 2011). For stable continental earthquake sources, there is little data to either confirm or contradict this model. In general, studies of correlation models have shown them to be relatively insensitive to the particular GMPM, earthquake magnitude, distance, and rupture mechanism (e.g., Baker, 2005; Jayaram et al., 2011). Thus, the numerical impact of using the single correlation model is anticipated to be relatively insignificant. Additional and/or updated correlation models corresponding to different earthquake sources and/or GMPMs could be incorporated into the web tool as they become available.

\section{Future features}

As mentioned above, in the future the USGS web tool will provide CS, not just CMS. The conditional standard deviations will likewise be calculated according to the aggregation approach to computing an exact CS. Whereas the current implementation for the conditional means has been seen to match results from the deaggregation approach of Method 4, the standard deviations of a CS calculated by the web tool are anticipated to be higher and more inclusive of all the uncertainties accounted for in the USGS National Seismic Hazard Maps.

Lastly, the current web tool calculates CMS with weights that are for exceedance of the $S a$ value specified by a user (via a selected mean exceedance probability). A future tool will provide weights for occurrence of an $S a$ value. In order to do so, the tool will optionally allow a user to specify an $S a$ value of interest, e.g., a Risk-Targeted Maximum Considered Earthquake $\left(M C E_{R}\right)$ ground motion value from ASCE (2010).

\section{Conclusions}

Approximate and exact computations of CS were proposed and used for example calculations for Stanford, Bissell and Seattle. Exact CS mean and standard deviation calculations can incorporate multiple GMPMs and causal earthquake $M / R / \theta$ combinations, as well as multiple seismic source models and their logic-tree branches. Varying levels of approximations were also considered, that replaced multiple $M / R$ combinations with simply the mean $M / R$ from deaggregation, and either considered only a single GMPM or performed an approximate weighting of several GMPMs. These approximations are potentially appealing because of their ease of computation and because they do not require deaggregation of GMPM weights - a result that is not yet widely available in conventional PSHA software.

The approximate CS calculations appear to be more accurate for conditional mean estimation than for conditional standard deviation estimation. The exact conditional standard deviation is always higher than approximate results because of the additional contribution from the variance in mean logarithmic spectral accelerations due to variation in causal earthquakes and GMPMs. The input causal earthquake parameters and the GMPMs used along with the corresponding weights affect the accuracy of the approximation in CS computation. Exact calculation methods may be needed for locations with hazard contributions from multiple earthquake sources, where errors 
from approximations are higher as a result of multiple contributing earthquake magnitudes and distances, and variation in predictions from the input GMPMs.

The exact CS calculations require extension of traditional PSHA deaggregation, which considers only magnitude, distance and $\varepsilon$, to deaggregation of GMPMs. This additional deaggregation output is now available as part of the hazard results provided by the USGS. Further, the USGS now provides CMS results using the exact calculation aggregation approach described here. These new calculation tools should be useful in facilitating hazard-consistent ground motion selection for nonlinear dynamic analysis, and will allow for exact spectra to be computed without requiring cumbersome calculations by users.

\section{Data and Resources}

Deaggregation and CMS data used in this study can be obtained from the USGS National Seismic Hazard Mapping Project website (http: //earthquake.usgs .gov/hazards), as part of the 2008 Interactive Deaggregations web tool at http://geohazards.usgs.gov/deaggint/2008/ (last accessed on June 18, 2012).

\section{Acknowledgments}

The authors thank Brendon Bradley, Gabriel Toro, Ned Field, Eduardo Miranda, and Ivan Wong for their helpful reviews of the paper. Also, thanks to Eric Martinez for his assistance on the USGS implementation. This work was supported by the USGS external grants program, under Awards 07HQAG0129 and 08HQAG0115. Any opinions, findings, and conclusions or recommendations presented in this material are those of the authors and do not necessarily reflect those of the funding agency.

\section{References}

Abrahamson, N. A. and L. Al Atik (2010). Scenario spectra for design ground motions and risk calculation. In 9th US National and 10th Canadian Conference on Earthquake Engineering, Toronto, Canada.

ASCE (2010). Minimum Design Loads for Buildings and Other Structures. ASCE 7-10. Reston, VA: American Society of Civil Engineers/Structural Engineering Institute.

ATC (2011). Guidelines for seismic performance assessment of buildings, ATC-58 100\% draft. Technical report, Applied Technology Council, Redwood City, California.

Atkinson, G. M. and D. M. Boore (2003). Empirical ground-motion relations for subduction-zone earthquakes and their application to Cascadia and other regions. Bull. Seismol. Soc. Am. 93(4), $1703-1729$.

Baker, J. W. (2005). Vector-valued ground motion intensity measures for probabilistic seismic demand analysis. Ph. D. thesis, Stanford University. 
Baker, J. W. (2011). Conditional mean spectrum: Tool for ground motion selection. J. Struct. Eng. 137(3), 322-331.

Baker, J. W. and C. A. Cornell (2006). Spectral shape, epsilon and record selection. Earthq. Eng. Struct. Dynam. 35(9), 1077-1095.

Baker, J. W. and N. Jayaram (2008). Correlation of spectral acceleration values from NGA ground motion models. Earthq. Spectra 24(1), 299-317.

Bazzurro, P. and C. A. Cornell (1999). Disaggregation of seismic hazard. Bull. Seismol. Soc. Am. 89(2), 501-520.

Benjamin, J. R. and C. A. Cornell (1970). Probability, Statistics, and Decision for Civil Engineers. New York: McGraw-Hill.

Beyer, K. and J. J. Bommer (2007). Selection and scaling of real accelerograms for Bi-Directional loading: A review of current practice and code provisions. J. Earthq. Eng. 11, 13-45.

Bommer, J. J. and F. Scherbaum (2008). The use and misuse of logic trees in probabilistic seismic hazard analysis. Earthq. Spectra 24(4), 997-1009.

Boore, D. M. and G. M. Atkinson (2008). Ground-motion prediction equations for the average horizontal component of PGA, PGV, and 5\%-damped PSA at spectral periods between $0.01 \mathrm{~s}$ and 10.0 s. Earthq. Spectra 24(1), 99-138.

Bradley, B. A. (2010). A generalized conditional intensity measure approach and holistic groundmotion selection. Earthq. Eng. Struct. Dynam. 39(12), 1321-1342.

Campbell, K. W. and Y. Bozorgnia (2008). NGA ground motion model for the geometric mean horizontal component of PGA, PGV, PGD and 5\% damped linear elastic response spectra for periods ranging from 0.01 to 10 s. Earthq. Spectra 24(1), 139-171.

Chiou, B. S. J. and R. R. Youngs (2008). An NGA model for the average horizontal component of peak ground motion and response spectra. Earthq. Spectra 24(1), 173-215.

Ditlevsen, O. (1981). Uncertainty modeling: with applications to multidimensional civil engineering systems. New York; London: McGraw-Hill International Book Co.

Goda, K. and G. M. Atkinson (2011). Seismic performance of wood-frame houses in south-western british columbia. Earthq. Eng. Struct. Dynam. 40(8), 903-924.

Gulerce, Z. and N. A. Abrahamson (2011). Site-specific design spectra for vertical ground motion. Earthq. Spectra 27(4), 1023-1047.

Harmsen, S. C. (2001). Mean and modal epsilon in the deaggregation of probabilistic ground motion. Bull. Seismol. Soc. Am. 91(6), 1537-1552.

Haselton, C., J. Baker, Y. Bozorgnia, C. Goulet, E. Kalkan, N. Luco, T. Shantz, N. Shome, J. Stewart, P. Tothong, J. Watson-Lamprey, and F. Zareian (2009). Evaluation of ground motion selection and modification methods: Predicting median interstory drift response of buildings. Technical Report 2009/01, Pacific Earthquake Engineering Research Center, Berkeley, CA. 
Jayaram, N. and J. W. Baker (2008). Statistical tests of the joint distribution of spectral acceleration values. Bull. Seismol. Soc. Am. 98(5), 2231-2243.

Jayaram, N., J. W. Baker, H. Okano, H. Ishida, M. W. McCann, and Y. Mihara (2011). Correlation of response spectral values in japanese ground motions. Earthq. Struct. 2(4), 357-376.

Jayaram, N., T. Lin, and J. W. Baker (2011). A computationally efficient ground-motion selection algorithm for matching a target response spectrum mean and variance. Earthq. Spectra 27(3), 797-815.

Katsanos, E. I., A. G. Sextos, and G. D. Manolis (2010). Selection of earthquake ground motion records: A state-of-the-art review from a structural engineering perspective. Soil Dynam. Earthq. Eng. 30(4), 157-169.

Kramer, S. L. (1996). Geotechnical earthquake engineering. Prentice-Hall International Series in Civil Engineering and Engineering Mechanics. Upper Saddle River, N.J.: Prentice Hall.

Lin, T. and J. W. Baker (2011). Probabilistic seismic hazard deaggregation of ground motion prediction models. In 5th International Conference on Earthquake Geotechnical Engineering, Santiago, Chile.

McGuire, R. K. (1995). Probabilistic seismic hazard analysis and design earthquakes: Closing the loop. Bull. Seismol. Soc. Am. 85(5), 1275-1284.

McGuire, R. K. (2004). Seismic hazard and risk analysis. Oakland, CA: Earthquake Engineering Research Institute.

Petersen, M. D., A. D. Frankel, S. C. Harmsen, C. S. Mueller, K. M. Haller, R. L. Wheeler, R. L. Wesson, Y. Zeng, O. S, D. M. Perkins, N. Luco, E. H. Field, C. J. Wills, and K. S. Rukstales (2008). Documentation for the 2008 update of the United States national seismic hazard maps: U.S. Geological Survey Open-File Report 2008-1128. Technical report.

Scherbaum, F., J. J. Bommer, H. Bungum, F. Cotton, and N. A. Abrahamson (2005). Composite ground-motion models and logic trees: Methodology, sensitivities, and uncertainties. Bull. Seismol. Soc. Am. 95(5), 1575-1593.

Somerville, P. G. and R. O. Hamburger (2009). Development of ground motion time histories for design. In Seismic Mitigation for Museum Collection: Papers from the J. Paul Getty Museum National Museum of Western Art (Tokyo) Jointly Sponsored Symposium, Tokyo, Japan.

Somerville, P. G. and H. K. Thio (2011). Development of ground motion time histories for seismic design. In Proceedings of the Ninth Pacific Conference on Earthquake Engineering, Auckland, New Zealand.

Watson-Lamprey, J. and N. A. Abrahamson (2006). Selection of ground motion time series and limits on scaling. Soil Dynam. Earthq. Eng. 26(5), 477-482.

Youngs, R. R., S.-J. Chiou, W. Silva, and J. Humphrey (1997). Strong ground motion attenuation relationships for subduction zone earthquakes. Seismol. Res. Lett. 68(1), 58-73. 
Zhao, J. X., J. Zhang, A. Asano, Y. Ohno, T. Oouchi, T. Takahashi, H. Ogawa, K. Irikura, H. K. Thio, P. G. Somerville, Y. Fukushima, and Y. Fukushima (2006). Attenuation relations of strong ground motion in Japan using site classification based on predominant period. Bull. Seismol. Soc. Am. 96(3), 898-913. 
(a)

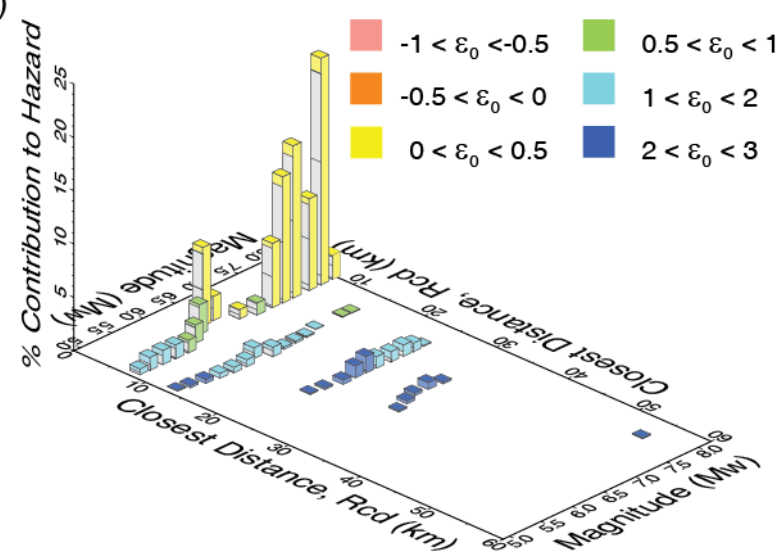

(b)

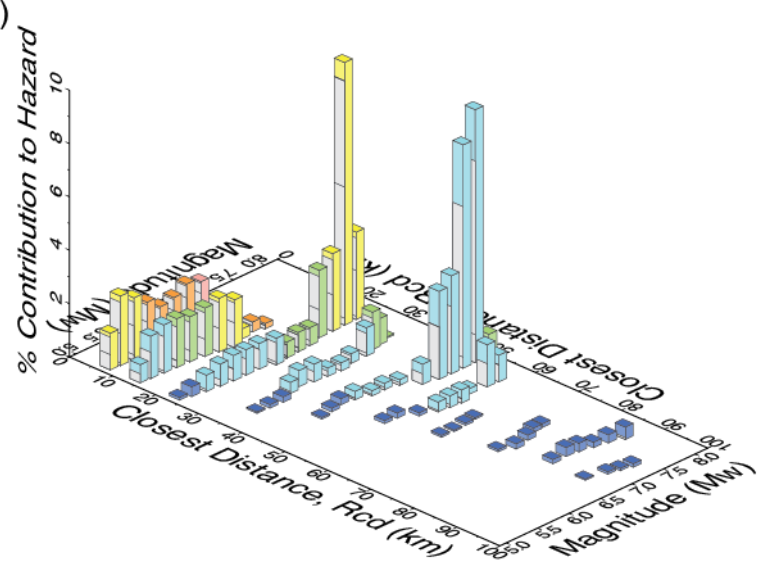

(c)

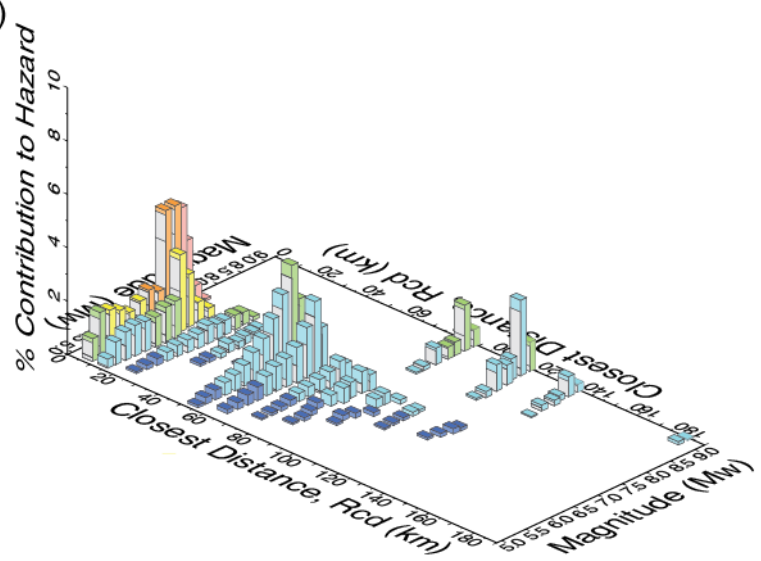

(d)

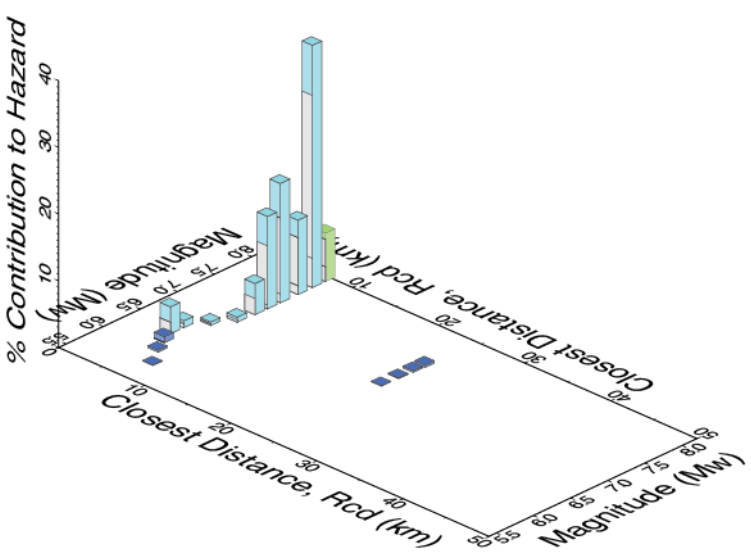

(e)

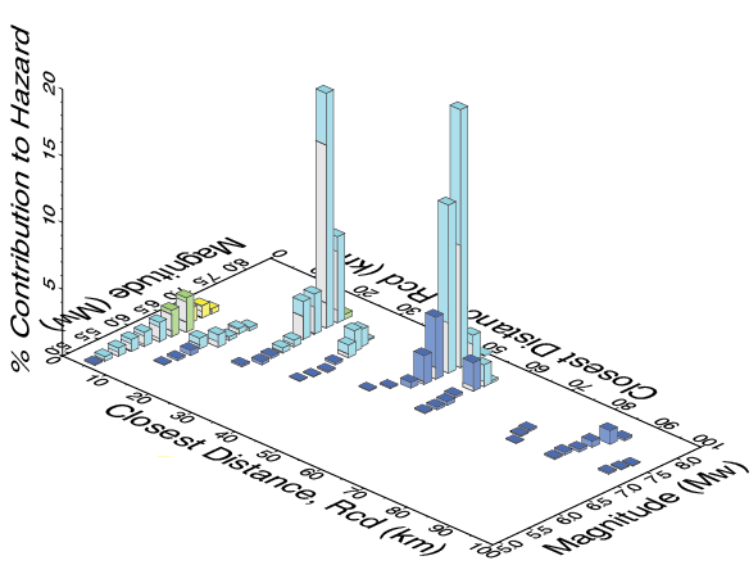

(f)

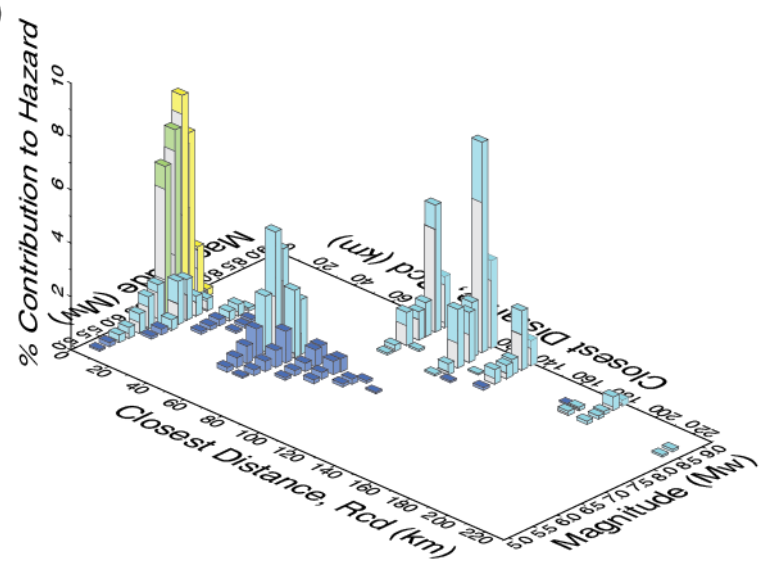

Figure 1: Deaggregation for $S a(0.2 s)$ with $10 \%$ probability of exceedance in 50 years at Stanford, Bissell, and Seattle (a, b, and c respectively) and for $S a(1 s)$ with $2 \%$ probability of exceedance in 50 years at Stanford, Bissell, and Seattle (d, e, and f respectively) (adapted with permission from USGS, see Data and Resources section). 
(a)

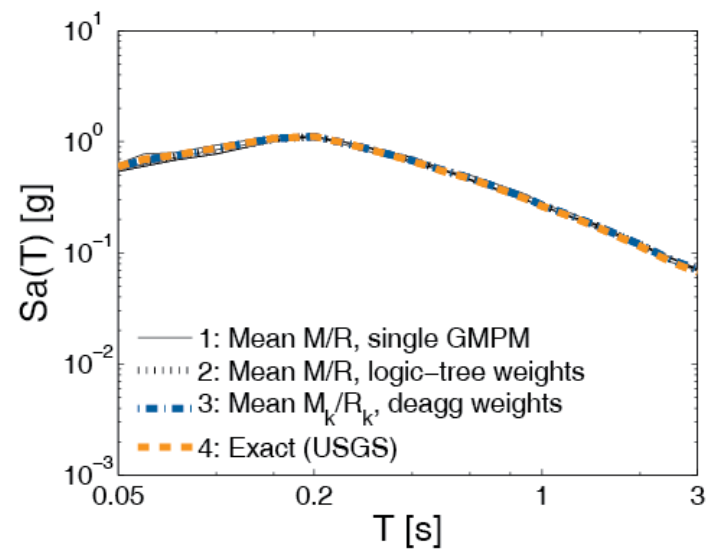

(b)

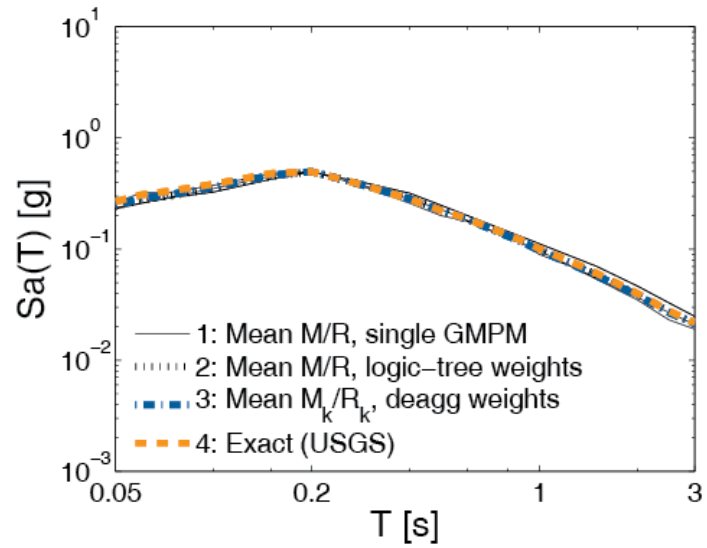

(c)

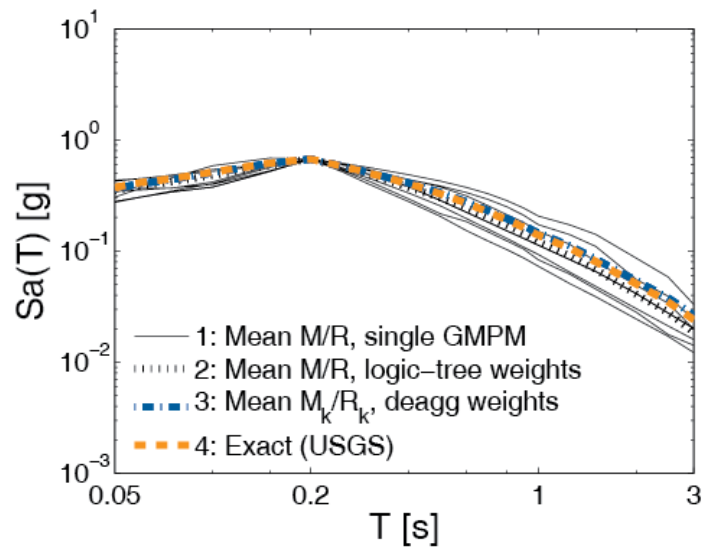

(d)

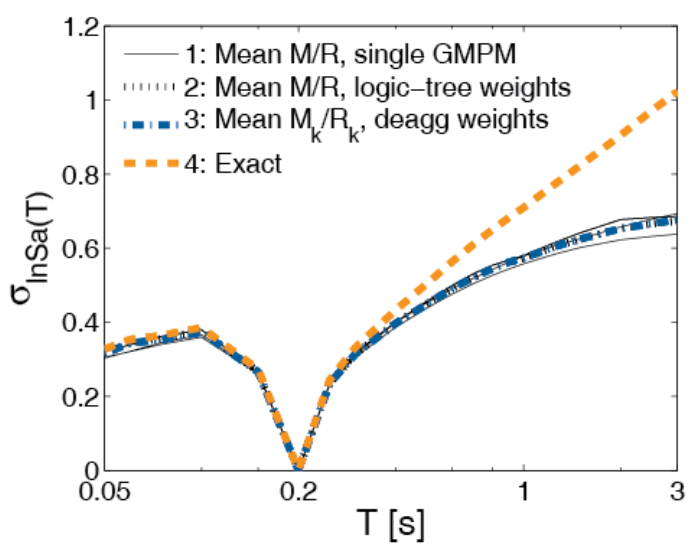

(e)

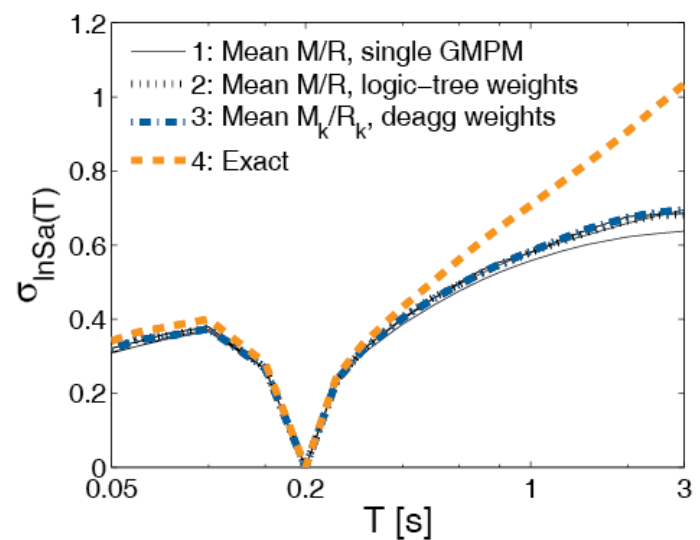

(f)

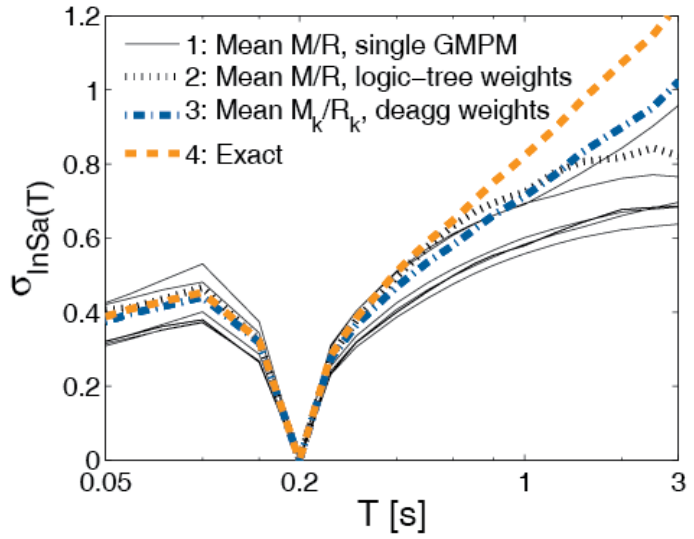

Figure 2: CMS at Stanford, Bissell and Seattle (a, b, and c respectively) and conditional standard deviation spectra at Stanford, Bissell, and Seattle (d, e, and f respectively) using Methods 1 to 4, for $S a(0.2 s)$ with $10 \%$ probability of exceedance in 50 years. 
(a)

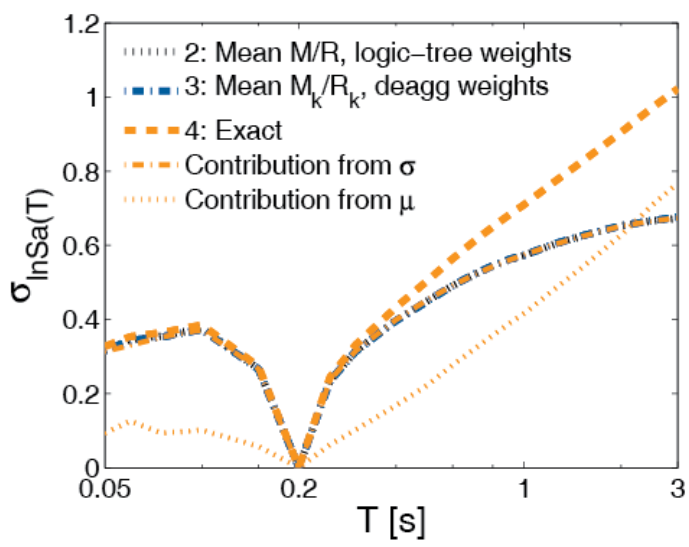

(b)

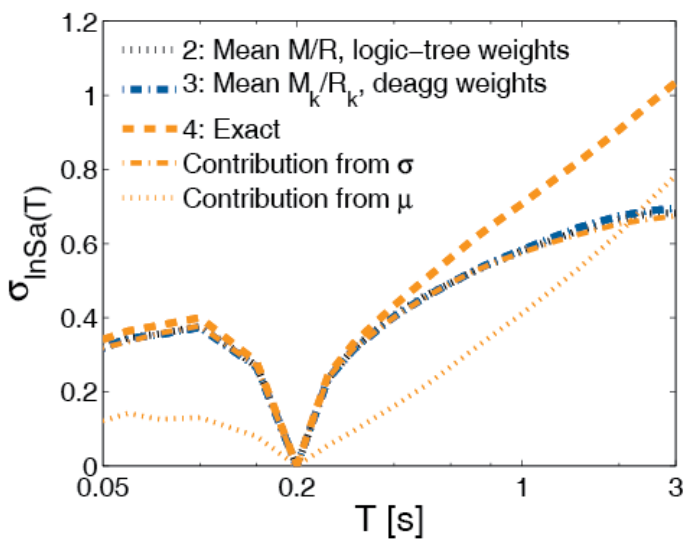

(c)

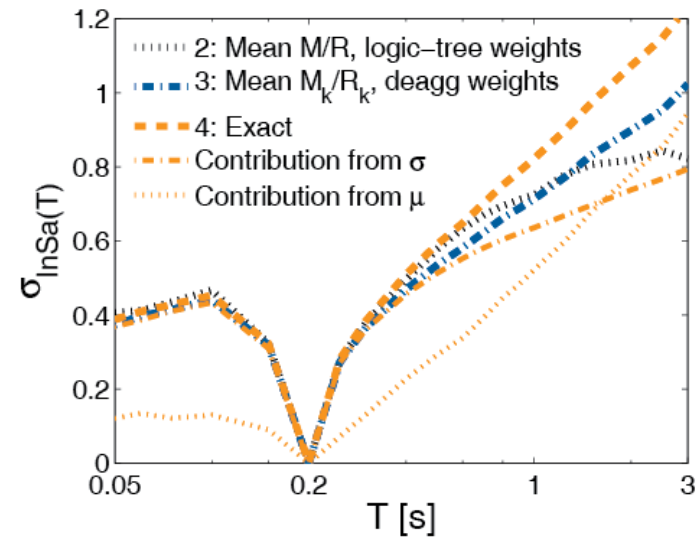

(d)

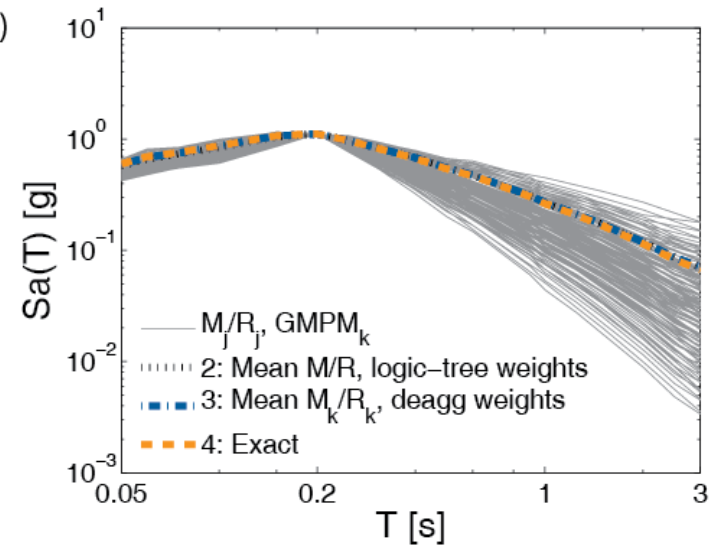

(e)

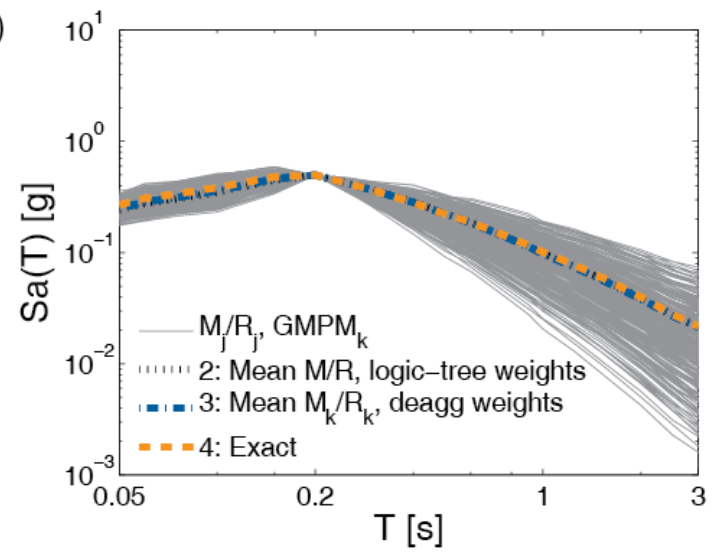

(f)

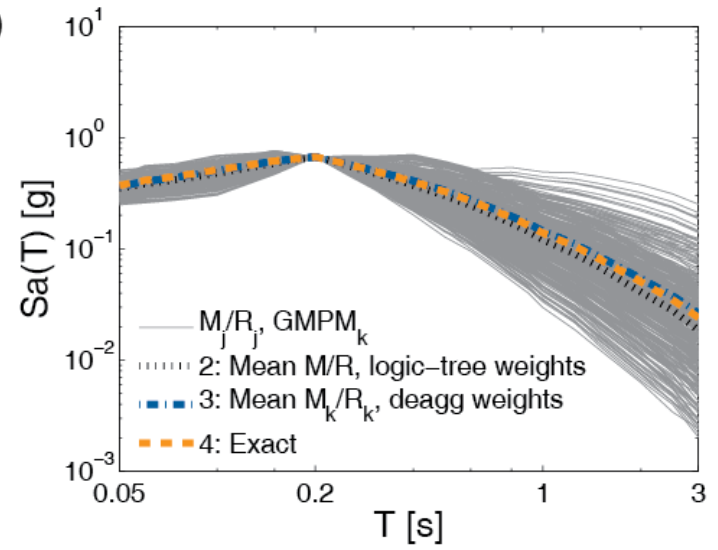

Figure 3: Conditional standard deviation spectra with contribution from $\sigma_{\operatorname{lnSa}}$ (variance in $\ln S a$ for a given $M_{j} / R_{j} \& G M P M_{k}$ ) and $\mu_{l n S a}$ (due to variation in $M_{j} / R_{j} \& G M P M_{k}$ ) at Stanford, Bissell, and Seattle (a, b, and c respectively) and CMS for each considered $M_{j} / R_{j} \& G M P M_{k}$ at Stanford, Bissell, and Seattle (d, e, and f respectively) using Methods 2 to 4, for $S a(0.2 s)$ with $10 \%$ probability of exceedance in 50 years. 
(a)

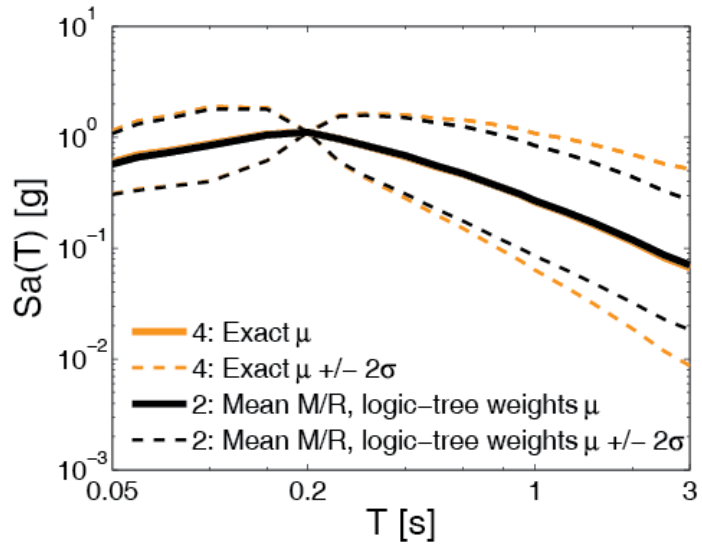

(b)

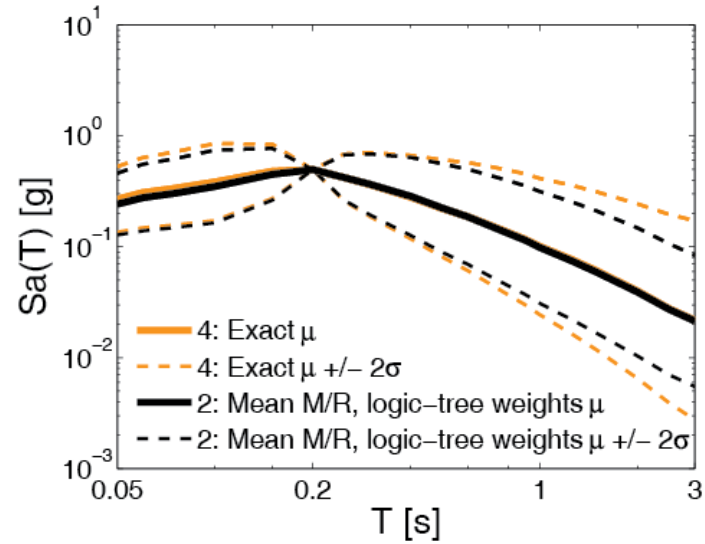

(c)

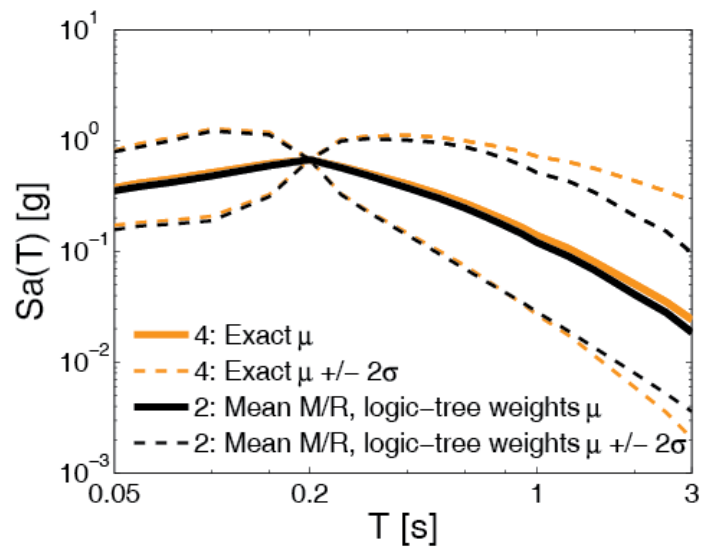

(d)

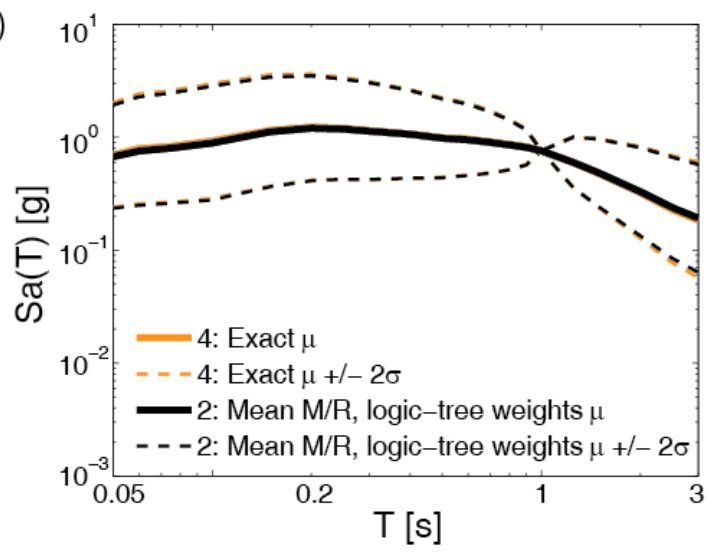

(e)

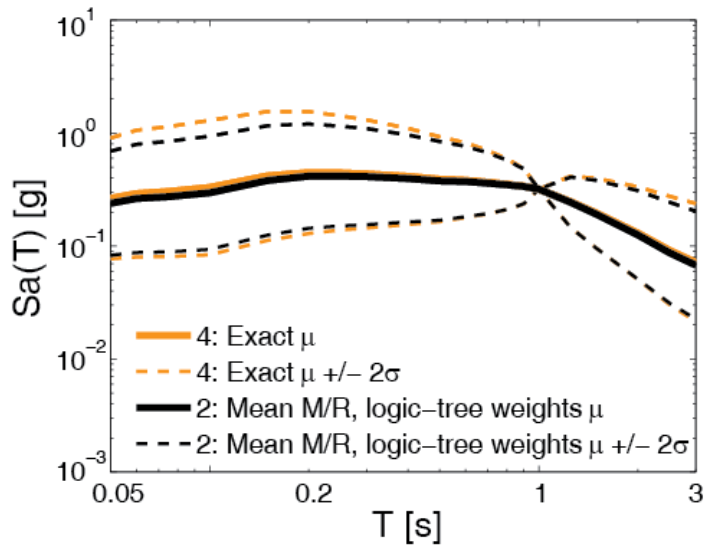

(f)

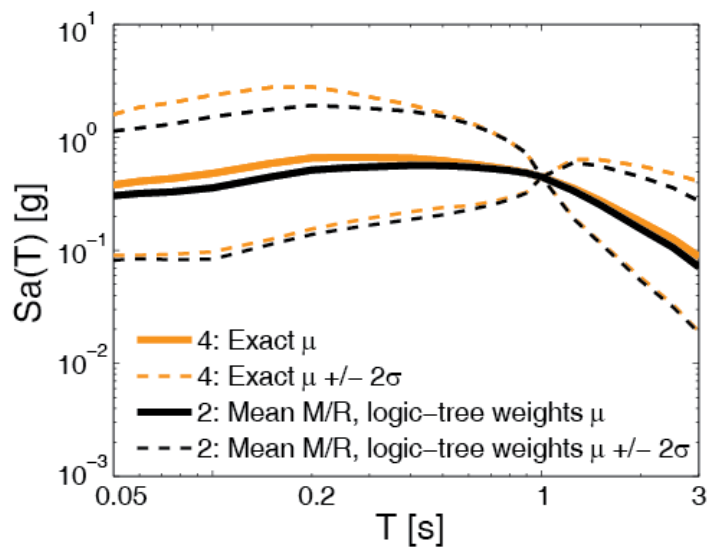

Figure 4: CS computed using Methods 2 and 4, for $S a(0.2 s)$ with $10 \%$ probability of exceedance in 50 years at Stanford, Bissell, and Seattle (a, b, and c respectively) and $S a(1 s)$ with $2 \%$ probability of exceedance in 50 years at Stanford, Bissell, and Seattle (d, e, and f respectively). 
(a)

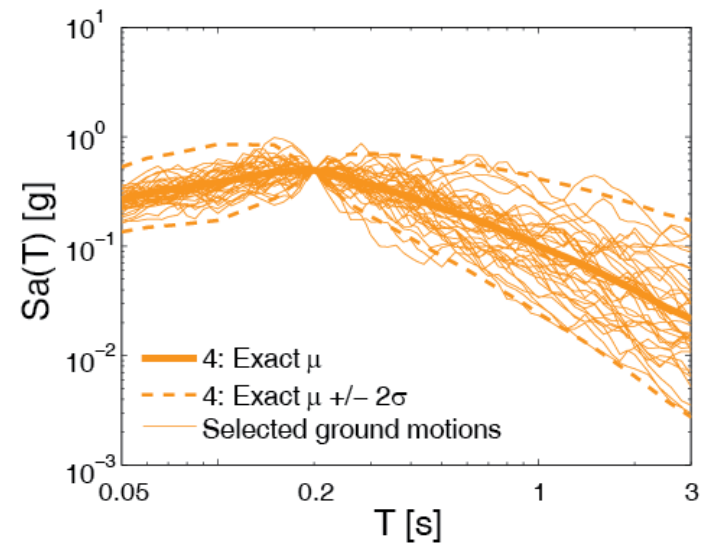

(b)

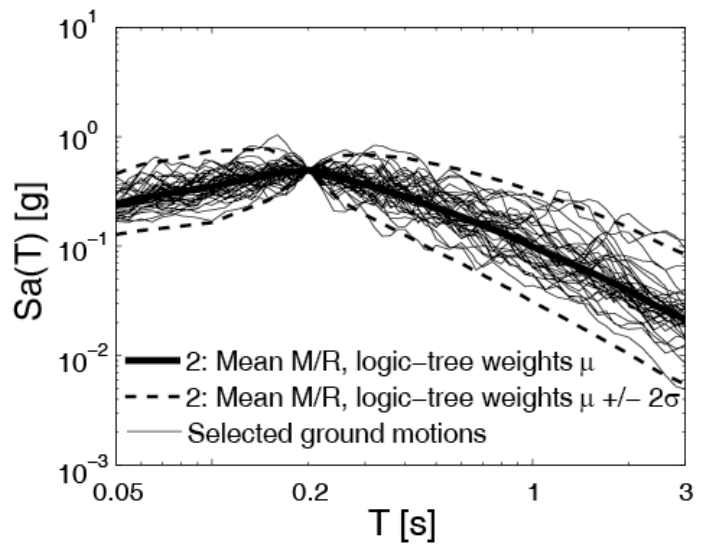

Figure 5: Response spectra of ground motions selected match CS obtained using (a) Method 4 and (b) Method 2 at Bissell site for $S a(0.2 s)$ with $10 \%$ probability of exceedance in 50 years.

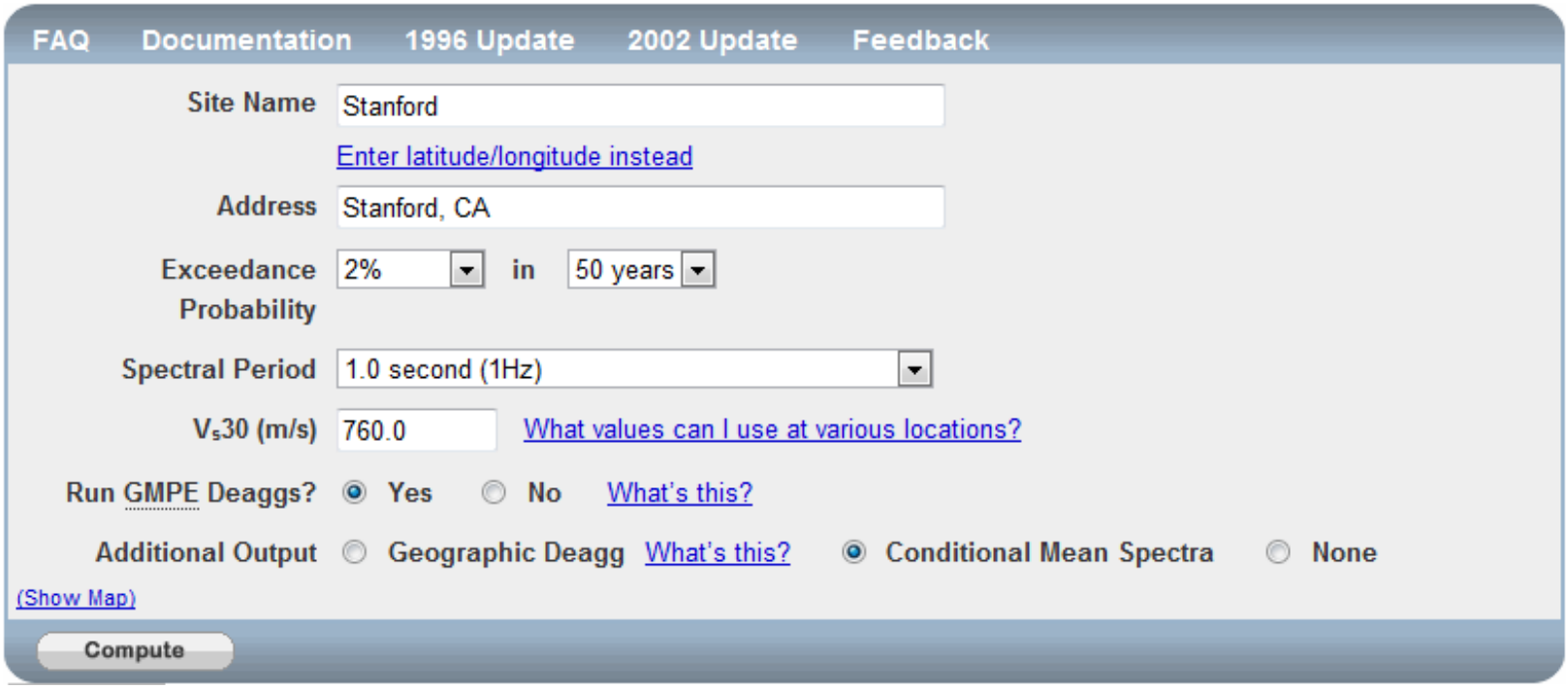

Figure 6: Interface for USGS online interactive deaggregations, including options to request GMPM deaggregation and CMS computation (reprinted with permission from USGS, see Data and Resources section). 